\title{
Knowledge of Bloom's Hierarchy of Cognitive Levels of Educational Objectives and its use in Setting Examinations by Nurse Educators in Lusaka and Eastern Provinces
}

\author{
Article by Patricia Mambwe \\ Lecturer, Rusangu University, Department of Nursing Sciences, School of Health Sciences, \\ Monze, Zambia \\ E-mail:mambwe.patricia@yahoo.com /mambwepatricia105@gmail.com
}

\begin{abstract}
Background: The use of Bloom's hierarchy of cognitive levels of educational objectives as a tool for classroom assessments is rapidly increasing therefore, Nurse Educators' knowledge of the tool is vital.

Objective: The first prime objective of this study was to investigate nurse educators' knowledge of Bloom's hierarchy of cognitive levels of educational objectives.

Materials and Methods: A cross sectional study was conducted in nursing training schools of Lusaka and Eastern provinces of Zambia. The study sample comprised of 63 Nurse Educators who were selected using purposive sampling method. A self-administered questionnaire was used to collect data from the respondents. Statistical Package for Social Sciences (SPSS) version 20 was used to analyse data. The Chi Square test was used to compare the proportions. A result yielding a $P$ value of less than 5 percent was considered to be statistically significant.

Results: The findings were that 64\% of nurse educators had low knowledge, $22 \%$ had moderate knowledge while $14 \%$ had high knowledge on Bloom's hierarchy of cognitive levels of educational objectives. Results from the study indicated that $90 \%$ of nurse educators affirmed that Continuing Professional Development meetings on assessment techniques were not conducted in the schools of nursing while $10 \%$ indicated that they had them.

Conclusion: Though the nurse educators undergo training on Bloom's taxonomy, their knowledge on this topic is low and calls for Continuous Professional Development Meetings. This will improve quality and standards of examinations in nursing education which will in turn improve the performance of nurses in the clinical area.
\end{abstract}

Keywords: Knowledge, use, Bloom's hierarchy, cognitive levels, educational objectives, setting examinations, Nurse Educators

\section{Introduction/Background}

Nurse educators are expected to produce critical thinking nurses. Critical thinking can only be stimulated from both classroom teaching and assessments using a classification such as Bloom's taxonomy. Assessments are most effective when more test items are written at the application or higher levels of cognition (De Young, 2009 and Garekwe, 2010). Zambia, being part of the global community, is expected to train critical thinking nurses. Studies done in other parts of the world such as the United States of America and South Africa indicated that nurse educators were concentrating more on setting knowledge/recall questions when evaluating students (Masters et al., 2001 and Garekwe, 2010).

\section{Statement of the problem}

Statistically, a study in America found that, $6 \%$ of the test items were prepared at the analysis level compared to $46 \%$ written at the knowledge level of Bloom's cognitive domain

(Masters et. al., 2001). In a related research done in South Africa, 57\% of the questions were prepared at lower cognitive levels while $43.4 \%$ were at higher cognitive levels (Garekwe, 2010). This is in direct 
DOI: $10.21522 /$ TIJNR.2015.03.02.Art008

ISSN: $2520-3126$

conflict when it comes to producing a critical thinking nurse for it is important to see to it that assessments match the philosophy of the curriculum and reflect all its educational outcomes (Garekwe, 2010; Azer, 2006; Mkandawire, 2013).

Questions in the lower order category of Bloom's cognitive domain do not promote critical thinking in a nurse instead; they become fertile manure in the production of a timid, dependent and robot-like nurse.

The researcher noted that from the inception of post basic nursing education in 1978 in Zambia (General Nursing Council of Zambia, 2002), no research has been conducted on questioning techniques during assessments. Literature has also reviewed that there is no information concerning nurse educators' use of Bloom's taxonomy during the preparation of test items for examinations. This is crucial as nurse educators' aim at producing critical thinking nurses.

It is against this backdrop that a study to evaluate the knowledge and usage of Bloom's hierarchy of cognitive levels of educational objectives in setting examinations by nurse educators has been undertaken.

\section{Materials and methods}

A cross sectional study was conducted in three (3) government nursing schools in the eastern part of Zambia namely Mwami, Chipata and St Francis nursing schools, one (1) government nursing school in Lusaka province namely Lusaka school of nursing, two (2) private nursing schools based in Lusaka province namely Dovcott College of Nursing and Lusaka Health Institute college of Nursing. Convenience sampling method was used to select nursing schools. Purposive also called judgemental sampling method was used to select nurse educators from selected nursing schools in Eastern and Lusaka provinces of Zambia to answer the questionnaire. The study sample comprised 63 nurse educators. The study used self-administered questionnaires.

Results: The findings were that $64 \%$ of nurse educators had low knowledge, $22 \%$ had moderate knowledge while $14 \%$ had high knowledge on Bloom's hierarchy of cognitive levels of educational objectives. Results from the study indicated that $90 \%$ of nurse educators affirmed that Continuing Professional Development meetings on assessment techniques were not conducted in the schools of nursing while $10 \%$ indicated that they had them.

\section{Presentation of the research findings}

\section{Respondents' knowledge levels on bloom's taxonomy}

The study solicited for information from the nurse educators on how they defined Bloom's taxonomy. The results have been shown in the figure below.

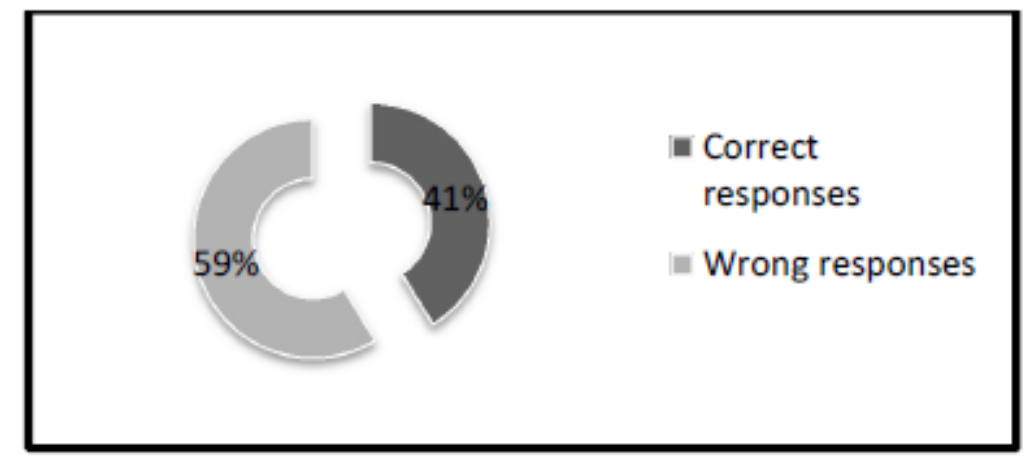

Figure 1. Definition of bloom's taxonomy

According to Figure 1 above, 26 (41\%) of the respondents defined Blooms Taxonomy correctly while $37(59 \%)$ did not define it correctly. Blooms Taxonomy is a tool used to classify learning objectives and to assess students' abilities (Krathwohl, 2002; Ferris and Azizi, 2005). 
In addition, the study also gathered information on the specific words used to classify test items in the lowest level of cognitive domain. The majority, 41 (65\%) of the respondents correctly stated that the words define, state and identify are the ones used to classify test questions in the lowest levels of cognitive domain.

Only $8(13 \%)$ of the respondents mentioned that the words state, explain, and convert are the ones used to classify test questions in the lowest levels of cognitive domain. $9(14 \%)$ thought the words explain, convert and create are the ones used whereas $5(8 \%)$ of the respondents thought create, identify and define are the words used. The mean was 1.6508 and the standard deviation was 1.00256 . The responses are illustrated in figure 2 below.

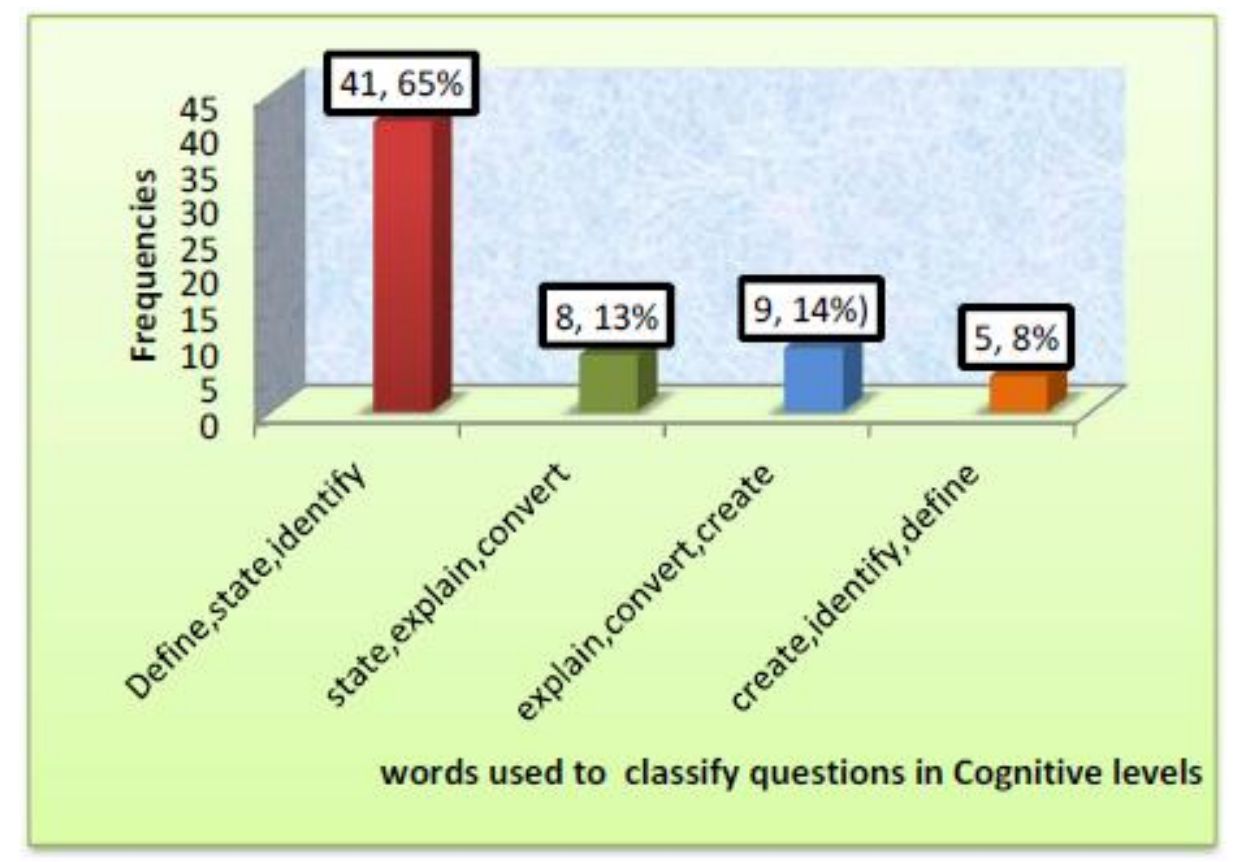

Figure 2. Words used to classify test questions in the lowest Level of cognitive domain $(n=63)$

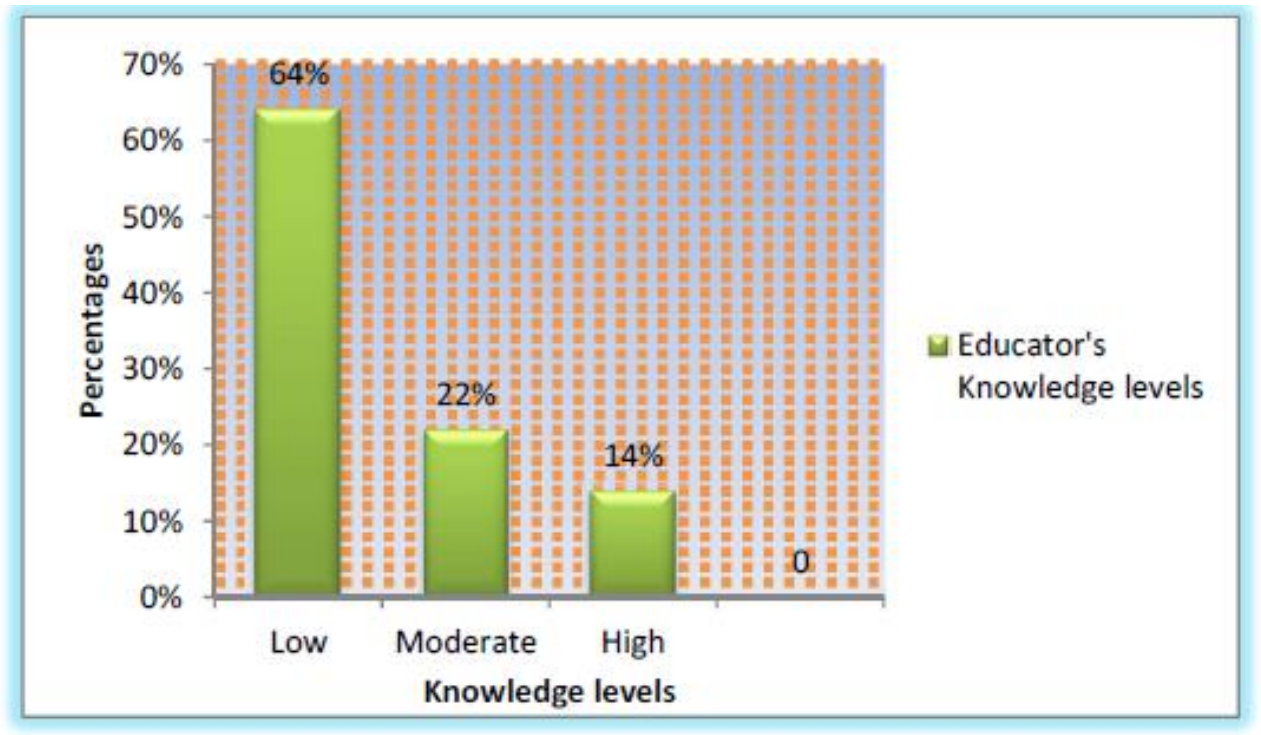

Figure 3. Nurse educators' knowledge levels on bloom's cognitive levels $(\mathrm{n}=63)$ 
DOI: $10.21522 /$ TIJNR.2015.03.02.Art008

ISSN: $2520-3126$

Figure 3 shows that majority, 64\% of nurse educators had low know on Bloom's cognitive levels

Use of cognitive levels of educational objectives when preparing test items by nurse educators

The second specific objective of this study was to determine the levels of cognitive domain assessed in examination papers. To achieve this objective, nurse educators were asked a number of questions to find out whether they used cognitive levels of educational objectives when preparing test items for examinations. The responses were recorded as shown in figure 4

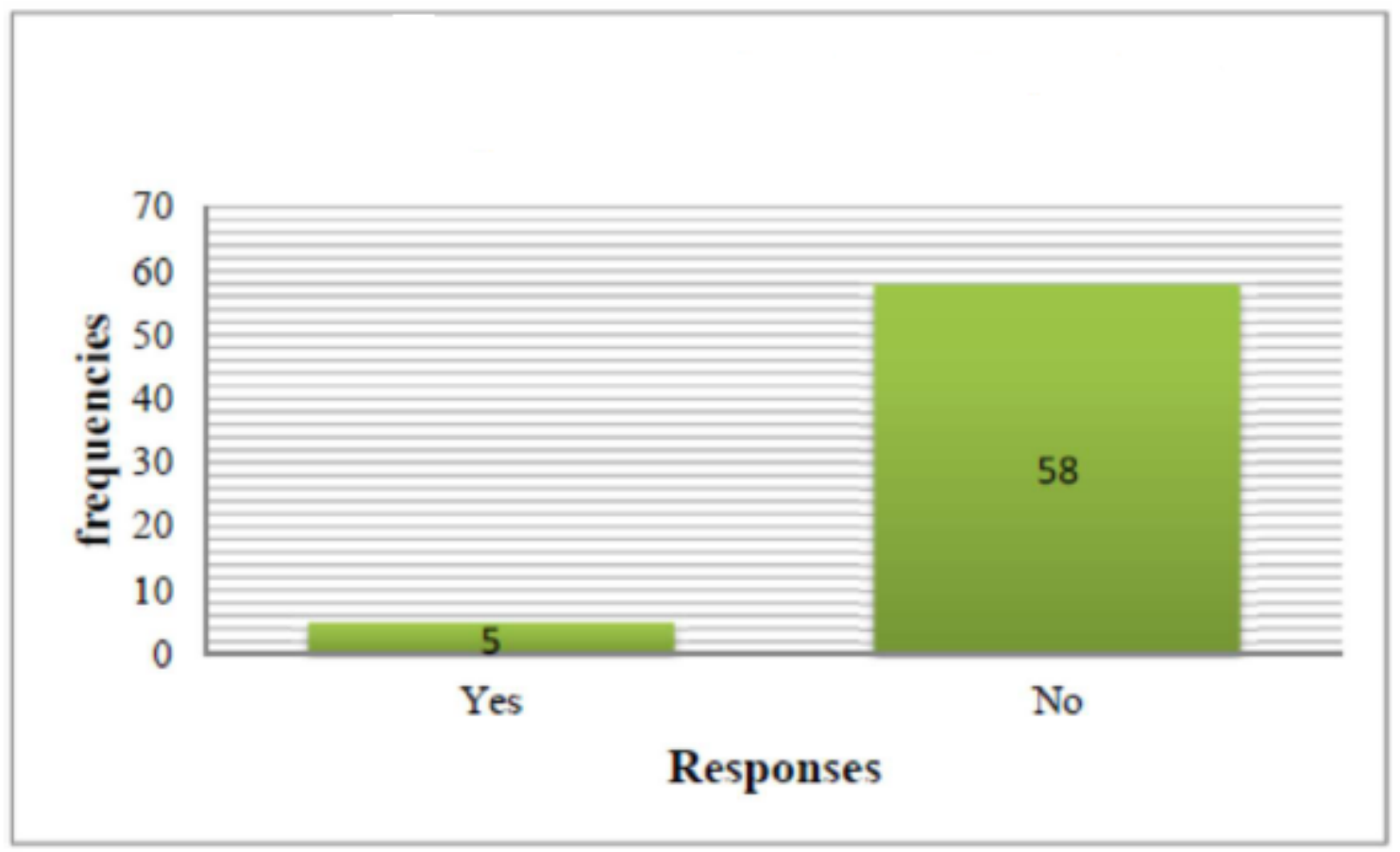

Figure 4. Following cognitive levels when setting examinations $(n=63)$

Figure 4 above indicates that $5(8 \%)$ of the respondents mentioned that they always followed the Bloom's hierarchy of cognitive levels of educational objectives when setting examinations whereas majority, 58 (92\%) stated that they did not.

\section{Use of standardized guidelines when preparing test items by nurse educators}

The analysis also gleaned information on whether nurse educators followed any standardized assessment guidelines when setting examination questions (preparing test items). The results are indicated in figure 5. 


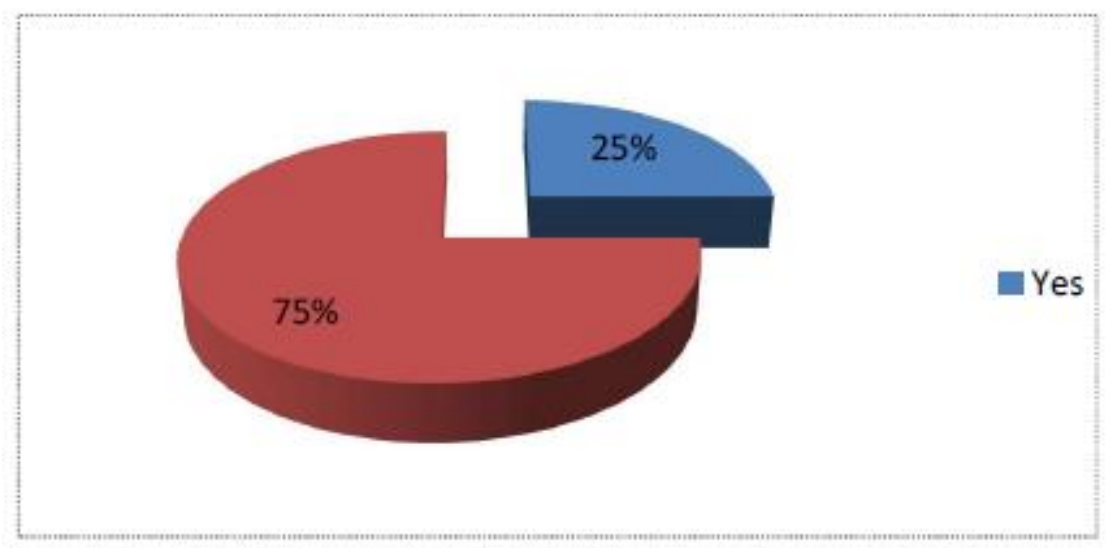

Figure 5. Following standardized assessment guidelines when setting examinations $(n=63)$

Based on data presented in Figure 5 above, 16 (25\%) of the respondents agreed that they used standardised guidelines for classroom assessment when setting examinations while the majority 47 (75\%) stated that they did not follow any standardised guidelines when setting examinations.

With regard to standardized guidelines, the study also gathered information on peer reviewing (moderation) of test items before they were administered to students. Nurse educators' responses are presented in the figure below.

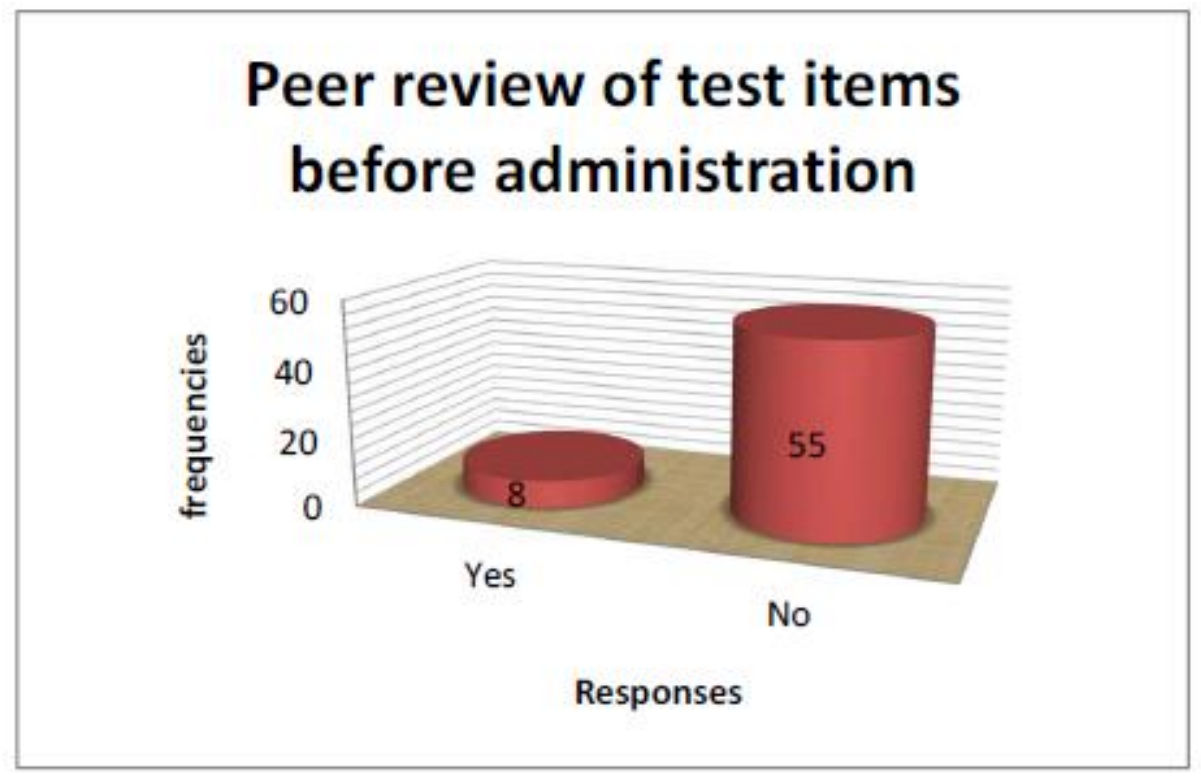

Figure 6. Peer review of test items before administration to students $(n=63)$

According to Figure 6 above, $8(13 \%)$ of the respondents agreed that a team(s)/committee peer reviewed the test items before being administered to the students, whereas majority, $55(87 \%)$ disagreed that they did not have their test papers peer reviewed before being administered to students.

Furthermore, the study acquired the responses nurse educators gave on the availability of a blue print in nursing schools. The findings indicated that only $4(6 \%)$ of the respondents had a blue print (table of specification) which act as a guide on how many questions to set in each cognitive level where as the rest $59(94 \%)$ of the respondents affirmed that they did not have any blueprint. Figure 7 gives a picture of the results. 
DOI: $10.21522 / \mathrm{TIJNR} .2015 .03 .02 . A r t 008$

ISSN: $2520-3126$

\section{Have Blue print which act as guide}

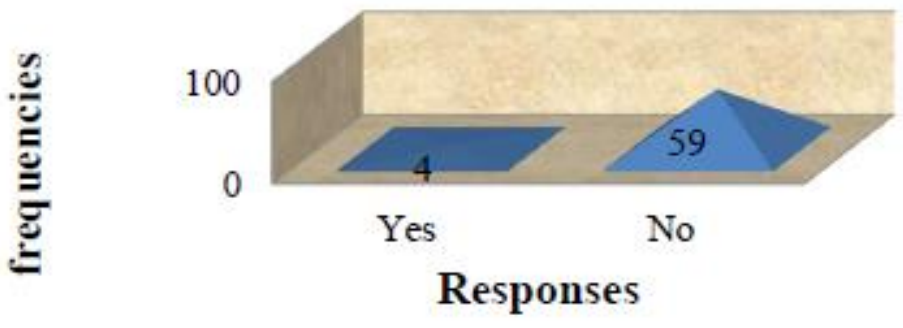

Figure 7. Have blue print which acts as a guide on number of questions to set in each cognitive level $(n=63)$

\section{Discussion}

Knowledge of Bloom's taxonomy is believed to be useful for educators to ask questions at various levels (Brown, 2001; Mkandawire, 2013; Cook, 2013). De young (2009) affirms that basic knowledge of Bloom's taxonomy would help educators to build an informational data base at lower level first before proceeding to higher levels of cognitive domain during teaching and assessments.

The findings in this study revealed that only $41 \%$ of the respondents defined Blooms taxonomy correctly whereas more than half $(59 \%)$ of the respondents did not know what Bloom's Taxonomy is. Bloom's Taxonomy is a tool used to classify learning objectives and to assess students' abilities (Krathwohl, 2002; Ferris and Azizi, 2005). This clearly demonstrates that less than the average number of nurse educators who participated in the study know what Bloom's taxonomy is. However, when an inquiry into the words that should be used to classify test questions in the lowest level of cognitive domain was made, $65 \%$ of the nurse educators gave a correct response whereas the rest $(35 \%)$ got it wrong. This could be the reason why a greater percentage of questions $(95 \%)$ were observed at lower order level compared to (5\%) at higher order in all the reviewed past question papers. Sithole (2011) argues that continuous usage of questions in the lowest cognitive domain serves no purpose in nursing since the nurse is expected to apply a scientific method in nursing in order to function as an independent practitioner.

Athanassiou, et al., (2003); Clauss and Geedey (2010); Cook, (2013); Agbedia and Ogbe (2014) affirms that it is important to know the cognitive levels of educational objectives as they are necessary for learning since they are classified in order of the complexity of the thought process involved. Surprisingly, the findings of this study revealed that a few (19\%) of the respondents knew the cognitive levels of educational objectives that promote critical thinking in students which are Application and Analysis as shown in the answer key.

Majority (81\%) did not know them. These results are similar to the findings in the study by Mkandawire (2013) who observed that teachers had no knowledge of cognitive levels that promote critical thinking. Studies by Garekwe (2010); Mkandawire (2013) ; Agbedia and Ogbe (2014) noted that knowledge and usage of cognitive levels that promote critical thinking facilitate the development of students' thinking ability, decision making and problem solving. This would have an impact on their performance and prepare them to be vigilant when caring for clients thereafter.

From the analysis of responses of nurse educators, it is interesting to note that only $8 \%$ of the respondents affirmed that they followed cognitive levels when setting examinations. A larger percentage (92\%) of the respondents mentioned that they did not follow Bloom's hierarchy of cognitive levels. The findings from the analyzed past examination question papers equaled the results above. The analysis revealed that questions were not set in application, analysis and evaluation levels of cognitive domain thus knowledge/recall and comprehension questions dominated. Mkandawire (2013) reported similar 
results and recommended that educators should be encouraged to follow cognitive levels of educational objectives during classroom assessments. Surprisingly, the greater percentage of the respondents (92\%) felt that following the cognitive level tool was important in nursing education while $(8 \%)$ of the respondents indicated that it was not important. Masters et al., (2001); Clauss and Geedey, (2010); Cook, (2013) observes that following taxonomies during assessments is important. However, factors such as shortages of nurse educators and time affect the adherence to taxonomies thereby hindering quality in assessments.

The study further excavated more pitfalls related to non-peer reviewing of test items. An investigation conducted on past examination papers showed that some of the questions prepared were unrelated to the program objectives. This was observed in mock and intermediate examinations of exiting students (finalists). A classic example of such parallel questioning includes matching of individual names with respective positions at the provincial health office. Such type of questioning not only has the potential to flair the percentage for general knowledge/recall questions in an assessment but also stands at crossroads in the promotion of higher order thinking among students. Garekwe (2010) and Reichert (2011) argues that repetition of questions in examination papers is associated to difficulties in the construction of own test items coupled with limited time to develop them. From this study, it is clear that most nurse educators prepared and administered test items to students without having a second person to look at them. This has serious implications in that tests may be of low quality and biased towards only one cognitive level of the Bloom's taxonomy.

Use of blue prints can effectively guide nurse educators to spread questions across cognitive levels of educational objectives. This view is supported by De Young (2009); Reichert (2011); Cook (2013). These scholars recommended the use of blue prints (table of specifications) as a guide on how many questions to set in each cognitive level. Contrary to this view, the findings in this study showed that very few (6\%) nurse educators had a blueprint for test items across the cognitive levels in their institutions while the majority (94\%) did not have. Additionally, the findings in this study revealed that only $3 \%$ of the respondents confirmed that they often times used the blue print whereas $5 \%$ said that they used the blueprint but not often. The majority (92\%) of the respondents either did not use the blue print or did not even respond to the question. It may be alleged that those who did not respond to the question did not know what a blue print is. This implies that examinations are mostly set without such a guide and as such there may not be a clear balance on the number of questions set in each cognitive level. The above findings from the questionnaires were complemented with the analysis done from the question papers. The analysis indicated a greater percentage $(88.5 \%$ ) of the set questions at basic knowledge (recall) level. This was followed by comprehension, $(6.4 \%)$ while the smaller percentages were observed at synthesis level with $(4.2 \%)$, analysis accounting for $(0.5 \%)$, application level, $(0.3 \%)$ and evaluation level at $(0.1 \%)$ respectively.

It was clear from the findings that an immense percentage of questions were prepared at the lower cognitive level than the higher cognitive level which promote critical thinking. The resounding negative implication is that the graduating nurses go in the ward to practice armed with a low thinking baby mind who entirely depends on the external orders from the clinicians.

No wonder, scholars such as Scheffer and Rubenfeld (2000); Agbedia and Ogbe (2014) observe that in the practical world of clinical nursing, critical thinking is the ability of nurses to see patients' needs and respond appropriately, beyond or in spite of the physicians' orders.

A critical thinker, said the scholars, goes beyond being a robot machine who simply does as he or she is told. Critical thinking is thus a crucial professional skill which goes hand in hand with clinical reasoning and clinical reflection (Sithole, 2011). The findings of this study match the results of the studies conducted by Mkandawire (2013), Reichert (2011), Garekwe (2010). These scholars observed that educators do not use a blue print to balance questions according to cognitive levels.

Continuing Professional Development (CPD) is a process by which educators keep up-to-date with knowledge and improve their skills in assessment techniques (Tarrant et al., 2006). 
DOI: $10.21522 /$ TIJNR.2015.03.02.Art008

ISSN: $2520-3126$

De young (2009) asserts that professional development meetings and other organized in-service programs are designed to foster the growth of educators that can be used for their further development. However, the findings of this study revealed that only $10 \%$ of nurse educators indicated that their departments conducted continuous professional development meetings on assessment techniques while the majority (90\%) did not (Figure 22). This is glairing evidence that CPD meetings were not conducted on a large scale in nursing schools. It is also highly probable that nurse educators who might have had participated in the CPD meetings did not share knowledge with other nurse educators on assessment techniques including the use of taxonomies. This was evidenced from the past examination papers analyzed in this study. Ultimately the standard of assessment was terribly compromised because in the final year of training, it is keenly expected that nursing students are assessed by appealing to questions and test items that promote higher order thinking.

Mkandawire (2013) notes that CPD is crucial because it enables educators to progress and develop their professional self, as well as remaining current with their skills and competencies. However, in his study also, $85 \%$ of teachers indicated that their departments did not conduct Continuing Professional Development meetings on classroom questioning.

Makandawire's findings are essentially a homologous to the findings of the studies by Tarrant et al., (2006); Masters et al., (2001); Clifton and Shriner (2010).

\section{Use taxonomies in asking questions either through tests, assignments or during lessons by nurse educators}

Curriculum designers and educators are expected to use the taxonomic model of teaching/ learning in their work. Commenting on the importance of using taxonomies, Kim et al., (2012) states that it is an ideal practice for educators to use guides when setting tests, assignments and examinations to ensure compliance to educational standards at all levels. The essence is to analyze and formulate questions according to cognitive levels. This is because the hierarchical levels of student learning can be used to determine the extent to which educators emphasize both lower and higher order thinking behaviours (Kim et al., 2012).

The findings of this study however, indicated that $46 \%$ of the respondents followed Bloom's Taxonomy in asking questions either through tests, assignments or during lessons while $54 \%$ did not. It is very clear from this finding that tests, examinations and assignments are usually set without any guide.

A similar observation was noted from the analyzed examination question papers that a colossal number of questions (74\%) were constructed using verbs which made students to only recall previously learned information. Recall type of questioning does not stimulate higher order thinking among students.

Mkandawire (2013); Kanter (2013); Kim et al., (2012); Krathwohl (2002) assert that, although it is now customary to write educational objectives as outcomes, lack of a systematic framework (Bloom's taxonomy) means that quality is not evident, or verifiable, and there could be a mismatch between the stated (intended) outcomes and the actual behavior of students.

It is therefore crucially important that nurse educators use Bloom's taxonomy when assessing students. However, studies by Reichert (2011) and Allen (2008) revealed that some factors like faculty shortages, lack of knowledge on Bloom's taxonomy, student population and time pose a big problem in the usage of Bloom's taxonomy in nursing education. The findings of this study also indicated that factors such as lack of time, knowledge on Bloom's taxonomy, inadequate orientation to test item preparation, large student numbers, poor attitude towards Bloom's taxonomy usage, no standard assessment guidelines, shortage of teachers and heavy workload affects use of the Blooms taxonomy when preparing test items in nursing. The study further indicated that majority of the respondents $92 \%$ strongly agreed that factors which affected nurse educators' usage of Bloom's taxonomy in questioning also affected performance of student nurses. On the other hand, $8 \%$ of the respondents argued that these factors did not affect student nurses' performance. 
Higher order thinking among students can be achieved if test items are spread across the cognitive levels. In this study, all (100\%) of the respondents indicated that asking questions at different levels of cognitive domain helps student nurses/learners to have critical thinking skills in nursing. The findings match the study results by Mkandawire (2013); Garekwe (2010); Boikhutso (2010); Kim (1996) who observed that a mixture of questions at various levels of the taxonomy during instruction and assessments promote critical thinking and induce different levels of student learning. Reichert (2011) and Garekwe (2010) further highlighted the advantage of having papers with mixed questions.

The two scholars indicated that low ability students performed better on knowledge/recall questions while high ability students performed better on application level questions. It is for this reason that, Kim (1996) affirms that the hierarchical levels of student learning can be used to determine the extent to which educators emphasize both lower and higher order thinking behaviours.

Surprisingly, application, analysis and evaluation levels remained at $0 \%$ throughout the years in some of the reviewed examination question papers (2011 to 2013) in this study. Krathwohl (2002); Garekwe (2010); Kim et al., (2012); Mkandawire (2013); Agbedia and Ogbe (2014) describes these levels as higher order levels in the cognitive hierarchy necessary for critical thinking. This clearly shows that the schools may produce students that will have problems with application, evaluation and analysis related issues during their nursing practice. These results are in line with findings by Zheng et al., (2008); Garekwe (2010) and Mkandawire (2013). One may link the higher number of questions which were asked at knowledge level (91\% and $92 \%$ ) to a problem of construction of questions.

Having a P-value of 0.001 clearly affirms that the relationship between ability to identify Bloom's hierarchy of cognitive levels of educational objectives that promote critical thinking in students and use of Bloom's hierarchy of cognitive levels of educational objectives is statistically significant.

Any serious intervention to improve the use of Bloom's hierarchy of cognitive levels of educational objectives should consider methods that will increase knowledge in this particular important dimension.

\section{Conclusion and Recommendations}

This study revealed that a greater percentage (64\%) of nurse educators had low knowledge on Bloom's hierarchy of cognitive levels of educational objectives. Despite low knowledge on Bloom's hierarchy of cognitive levels of educational objectives, majority, $90 \%$ of nurse educators affirmed that Continuing Professional Development meetings on assessment techniques were not conducted in the schools of nursing. Based on these findings, the author recommends that Continuing Professional Development meetings, workshops and seminars on questioning techniques should be developed and made mandatory for all academic staff in all the schools of nursing. This will improve quality in nursing education and keep all nurse educators abreast with the current information on questioning techniques and on Bloom's hierarchy of cognitive levels of educational objectives.

\section{References}

[1].Affiliated Health Training Institutions (2004). Assessment standards for semesterised and non semesterised programs. Gaborone, Botswana.

[2].Agbedia, C and Ogbe, J. (2014). Critical thinking; issues in nursing education and practice. International Journal of Advanced Nursing Studies, 3 (1) 13 - 17. http://www.sciencepubco.com/index.php/IJANS accessed on 06/03/14 at 11: 14 hours.

[3].Allen, L. (2008). The Nursing shortage continues as faculty shortage grows. Nursing Economics, 26 (1) 35 - 40. http://www.ncbi.nlm.nih.gov/pubmed/18389840. accessed on 9/3/14 at 09:30 hours.

[4].American Nurses Association. (2001). Code of ethics for nurses with interpretive statements. Washington, DC. American Nurses Publishing Company. http://www.vcuhealth.org. Accessed on 9/3/14 at 10:01 hours.

[5].Anderson, L. W, David R. and Krathwohl, D. R., et al (Eds.). (2001). A Taxonomy for Learning, Teaching, and Assessing: A Revision of Bloom's Taxonomy of Educational Objectives. Allyn \& Bacon. Boston, MA (Pearson Education Group). Http://www.odu.edu/educ/roverbau/Bloom/bloom's taxonomy.htm accessed on 12/02/14 at 15 hours. 
DOI: $10.21522 /$ TIJNR.2015.03.02.Art008

ISSN: $2520-3126$

[6].Athanassiou, N. McNett, J.M and Harvey, C. (2003). Critical thinking in the management classroom: Bloom's Taxonomy as a learning tool. Journal of Management Education, 27(5) 533 - 55. http://eric.ed.gov/?id=EJ675756 accessed on 10/04/14 at 14:30 hours.

[7].Ayvaci, H.S and Turkdogan, A. (2010). Analysing "Science and Technology Course exam questions" according to Revised Bloom's Taxonomy. Turkish Science Education, 7 (1) 13 - 25. http://ebookily.net/doc/res-351-finalexam. accessed on 28/01/14 at 14:50 hours.

[8].Azer, S. A. (2006). Assessment in a problem based learning course: Twelve tips for constructing multiple choice questions that test student's cognitive skills. Biochem.Mol.Biol.Educ., $31(6) \quad 428 \quad-\quad 434$. http://onlinelibrary.wiley.com accessed on 14/03/14.

[9].Bailey, L.R. (2011). Standardized procedure guidelines. Retrieved from http://www.rn.ca.gov/regulations/title16.shtml\#1470. accessed on 11/5/15 at 17:21 hours.

[10]. Bandaranayake, R. (2008). Setting and maintaining standards in multiple choice examinations. AMEE guide No. 37, medical teacher, 30 (9) 836 - 845. http://www.ncbi.nlm.nih.gov/pubmed/19117221. accessed on 9/3/14 at 11:30 hours.

[11]. Beekman, L. (2000). Problem solving and decision making strategies skills: A co - curriculum teaching thinking skills for nursing students. South Africa: Van Schaiki.

[12]. Blanchette, J. (2001). Journal of Distance Education. Royal Roads University, Victoria, BC. http://www.cade.athabascau.calvo116.2/blanchette.html. accessed on 9/3/14 at 16:05 hours.

[13]. Bloom, B. S. (1956). Taxonomy of Educational Objectives: The classification of educational objectives. New York. David McKay. http://www.officeport.com/edu/bloom.htm. accessed on 03/3/14 at 08:20 hours

[14]. Boikhutso, K. (2010). The theory into practice dilemma: lesson planning challenges facing Botswana student teachers. http://imp.sapub.com/content/13/3/205 accessed on 24/02/2014 at 20:54 hours.

[15]. Brady, A. M. (2005). Assessment of learning with multiple choice questions, 5 (4) 238 - 42. Journal for Nurse Education and Practice. http://www.ncbi.nlm.nih.gov/pubmed/10938205. accessed on 10/04/14 at 15:06 hours.

[16]. Bradley, M. et al (2007).Ask and you will receive: How question types influences quantity and quality of online discussions. British Journal of Educational Technology, 39, 888-900.

[17]. Brown, G. (2001). Assessment: A Guide for lecturers. http://78.158.56.101/achive/palatine/files/980.pdf accessed on 14/03/14 at 07: 55 hours.

[18]. Bumen, N. T. (2007). Effects of the original versus revised Bloom's Taxonomy on lesson planning skills: a Turkish study among pre-service teachers. Review of Education, 53, 439 - 455.

[19]. Burns, N and Grove, S. K. (2009). The Practice of Nursing Research: Appraisal, Synthesis, and Generation of Evidence. 6th edition, Saunders Elsevier.

[20]. Clauss, J and Geedey, K. (2010). Knowledge Surveys: Students ability to self - assess, 10(2) 14 - 24. Journal of the scholarship of Teaching and Learning. http://dmc.augustana.edu/ks/Accessed on 21/04/14 at 06:30 hours.

[21]. Clifton, S and Schriner, C. (2010). Assessing the quality of multiple choice test items. Nurse educator, 35(1) 12 - 16. http://www.ncbi.nlm.nih.gov/pubmed/20010262. accessed on 9/3/14 at 15:05 hours.

[22]. Considine, J. Bott, M. and Thomas, S (2005). Design, format, validity and reliability of multiple choice questions for use in nursing research and education. Collegian, 12 (08) 19 - 24. http://www.academia.edu/737711/Design,format,validity Accessed on 9/3/14 at 14 hours.

[23]. Cook, J. (2013). How can a teacher use Bloom's taxonomy in the classroom? Retrieved June 26, 2014 at 19:49 hours from http://www.ehow.com/way-5809221

[24]. De Young, S (2009). Teaching Strategies for Nurse Educators. 2nd edition, New Jersey: Prentice Hall.

[25]. Downing, S. (2005). The effects of violating standard item writing principles on tests and students: The consequences of using flawed test items on achievement examinations in medical education, 10 (2) $133-143$. http://www.ncbi.nlm.nih.gov/pubmed/16078098. accessed on 9/3/14 at 17:10 hours.

[26]. Eber, P.A and Parker, T.S (2007). Assessing student learning: applying Bloom's Taxonomy. Human Service Education, 27(1) 45 - 53. http://www.lesn.appstate.edu/olson/RES5560/course-components/student-work. accessed on $13 / 03 / 14$ at $20: 08$ hours.

[27]. Edwards, S (2003). Critical thinking at bedside: a practical perspective. British Journal of Nursing, 12(19) 


\section{Texila International Journal of Nursing}

Volume 3, Issue 2, Dec 2017

1142-1149. http://www.britishjournalofnursing accessed on 9/3/2014 at 22:15 hours.

[28]. Ellis, K (1993). Teacher questioning behaviour and student learning: What research says to teachers? Paper presented at the 64th annual meeting of the Western States Communication Association, Albuquerque. http://eric.ed.gov/?id=ED359572 accessed on 10/3.2014 at 20:31 hours.

[29]. Ferris, L.J. and Azizi, S.M. (2005). A psychomotor Skills Extension to Bloom's Taxonomy of Education Objectives for Engineering Education. University of South Australia, Mawson Lakes, 5095, Australia: Putney Publishing.

[30]. Fesler - Birch, D.M (2005). Critical thinking and practical outcomes. A review. Nursing outlook, 53(2) 59 65.

[31]. Garekwe, M (2010). Analysis of cognitive levels of examination questions set in the Bachelor of Nursing Programme at the University of KwaZulu-Natal. Masters dissertation in Nursing Education. http://hdl.handle.net/10413/244 accessed on 25/2/2014 at 20:49 hours.

[32]. General Nursing Council of Zambia (2005): The Nursing Regulatory Framework. Lusaka, Zambia.

[33]. Goodman, B (2011). The sociological imagination, provocative pedagogy and scholarship: re-valuing thinking and writing in nurse education. Nurse Education Today. http://www.ncbi.nih.gov/pubmed/21496975. accessed on 13/04/14 at 21: 26 hours.

[34]. Haladyna, T.M., Downing, S.M., and Rodriguez, M.C (2002). A review of multiple - choice item writing guidelines for classroom assessment. Applied measurement in education, 15(3) 309-334. Http://download.springer.com/.../pdf/10.1007\%2Fs12630-011-9467-9 accessed on 14/07/2014 at 09:13 hours.

[35]. Hard, J (2010). Creating tests that assess higher order thinking skills. http://www.cfcc.edu/SACS/QEP/testshigher-thinking.ppsx accessed on 10/04/14 at 14:47 hours.

[36]. Jozefowicz, R. Koeppen, B. Case, S. Galbraith, R. Swanson, D. Glew, R (2002). The effects of violating standard item writing principles on tests and students: the consequences of using flawed test items on achievement examinations in medical education, 77(2) $156-161$

[37]. Kantar, L. D (2013). Assessment and instruction to promote higher order thinking in nursing students. http://www.ncbi.nlm.nih.gov/pubmed/24035312 accessed on 31/03/14 at 14:44 hours.

[38]. Kastberg, S.E (2003). Using Bloom's Taxonomy as a framework for classroom assessment. The mathematics teacher, 96(6) 402 - 405. http://www.ipcsit.com/vol136/005-ICIIM2012-M0017 accessed on 25/03/2014 at 16:11 hours.

[39]. Kim, S. Phillip, W.R. Pinsky, L. Brock, D. Phillips, K. and Keary, J (1996). A conceptual framework for developing teaching cases. A review and synthesis of the literature across disciplines. Journal of Medical Education, 40(9) 867 - 876. http://onlinelibrary.wiley.com accessed on 09/03/14 at 01:14 hours.

[40]. Kim, M. Patel, R. Uchizono, J, Beck, L (2012). Incorporation of Bloom's Taxonomy into multiple - choice examination questions for a pharmacotherapeutics course. American Journal of Pharmaceutical Education, 76(6) 14. http://www.ncbi.nlm.nih.gov/pubmed/22919090. accessed on 28/01/2014 at 15:16 hours.

[41]. Krejcie R. V., And Morgan D. W., (1970): Determining Sample Size for Research Activities. Educational and Psychological Measurement. Published formula for determining sample size. ... The relationship between sample size and total population illustrated in Figure 1. Accessed on 6/05/2014 from http://home.kku.ac.th/sompong/guest_speaker/KrejcieandMorgan_article.pdf.

[42]. Knapp, R. (2014). Continuing Nursing Competency. Http://thenetstudyguide.com accessed on 14/03/14 at 13: 15 hours.

[43]. Krathwohl, D. R (2002). A revision of Bloom's Taxonomy: An overview. Theory into practice, 41(4) 212 218. http://www.jstor.org/stable/1477405. accessed on 14/03/14 at 07:30 hours.

[44]. Krau, (2011). Creating educational objectives for patient education using the new Bloom's Taxonomy, 46(3) 299 - 312. http://dx.doi.org/10.1016/j.cnur accessed on 14/03/14 at 14:50 hours.

[45]. Masters, J. Hulsmeyer, B. Pike, M. Leichty, K. Miller, M. and Verst, A (2001). Assessment of MCQ in selected test banks accompanying text books used in nursing education. Journal of nursing education, 40(1) $25-32$. http://www.ncbi.nlm.nih/gov/pubmed/11198906. accessed on 10/3/14 at 08:00 hours.

[46]. Ministry of Health (2006 to 2011) National Health strategic Plan, Lusaka, Zambia. 
DOI: $10.21522 /$ TIJNR.2015.03.02.Art008

ISSN: $2520-3126$

[47]. Mkandawire, C. (2013). Teachers Questioning techniques in Mathematics at Grade 11 level: The case of four selected secondary schools in Petauke District. Masters dissertation in Education. University of Zambia.

[48]. Moreno.R., Martinez, R., and Muniz, J (2006). New guidelines for developing multiple - choice items. Methodology, 2(2) 65 - 72. http://www.psycontent.com/index/X1817H71H93018T6.pdf accessed on 11/4/14 at 9:26 hours.

[49]. Morrison, S. and Walsh Free, K. (2001). Writing Multiple Choice test items that promote and measure critical thinking. Journal of Nursing Education, 40(1) 17-24. http://www.researchgate.net/publication/12/3208/. Accessed on 9/3/2014 at 19:30 hours.

[50]. Msidi. E.J., (2010): The General Nursing Council of Zambia: Registered Critical Care Nursing Curriculum. Zero Draft, Lusaka.

[51]. Mukarugwiza, F. (2003). Analysis of the cognitive level of basic nursing examinations in Rwanda. Durban, South Africa.

[52]. National League for Nursing. (2005). Core competencies of Nurse Educators. Retrieved from http://www.nln.org/profdev/corecompetencies.pdf

[53]. Nicholl, M. and Tracey, C. (2007). Questioning: A tool in the nurse educators' kit; 7, 285 - 295. Journal for Nurse Education in Practice. http://gamenuig.files.wordpress.com accessed on 20/09/2015 at 20:41 hours.

[54]. Nkonde (2014). Chilenje patient dies on the queue. http://www.postzambia.com accessed on 20/03/14 at 04:34 hours.

[55]. O’Neill, G. (2010). Overview of curriculum models program design. UCD Teaching and Learning Resources. http://www.ucd.ie/teaching accessed on 13/03/14 at 19:50 hours.

[56]. Palmer, E. and Devitt, P. (2007). Assessment of higher order cognitive skills in undergraduate education: modified essay or multiple choice questions? Research paper, medical education, 49 (7) 7 - 4 . http://www.biomedcentral.com accessed on 03/03/14 at 09:30 hours.

[57]. Pardue, S.F. (1987). Decision - making skills and critical thinking ability amongst associate degree, diploma, baccalaureate and masters - prepared nurses. Journal of Nursing Education, 26 (9) 354 - 361. http://www.ncbi.nlm.nih.gov/pubmed/2830374. accessed on 13/03/14 at 18: 06 hours.

[58]. Phillips, N. and Duke, M. (2001). The questioning skills clinical teachers and preceptors: A comparative study. Journal of Advanced Nursing, 33 (4) 523 - 532. Available at academic search premier database. Accessed on 02/03/14.

[59]. Polit, D. F. and Beck, C. T. (2008). Generating and Assessing Evidence for Nursing Practice, 8th edition, Lippincott, Philadelphia.

[60]. Polit. D.F and Hungler. B. (2001): Nursing Research, Principles and methods,

Lippincott, Philadelphia.

[61]. Profetto - Mcgrath, J. Smith, K. Day, R. and Yonge, O. (2008). The questioning skills of tutors and students in a context based baccalaureate nursing program. Nursing Education Today, 24(5) 363 - 372.

[62]. Reichert, T.G. (2011). Assessing The Use of High Quality Multiple Choice Exam Questions in Undergraduate Nursing Education: Are Educators Making the Grade? Masters of Arts in Nursing Thesis. St. Catherine University. http://Sophia.stkate.edu/cgi/viewcontent. accessed on 14/03/14 at 07:15 hours.

[63]. Russel, A. Comello, R. Wright, D (2007). Journal of Education and Human Development, 1(1) 1934 - 7200. http://www.scientificjournals.org/journals2007/articles/1025.htm

[64]. Scheffer, B and Rubenfeld, M (2000). A consensus statement on critical thinking in nursing. Journal of Nursing Education, 39(8) $352-60$.

[65]. Sellappah, S. Hussey, T. Blackmore, A. and McMurray, a (1999). The use of questioning strategies by clinical teachers. Journal of Advanced Nursing, $28(1) \quad 142 \quad-\quad 149$. http://ahn.mnsu.edu/nursing/facultyformsandinfo/clinicalquestioning.pdf accessed on 13/03/14 at 19:43 hours.

[66]. Sithole, P. C. (2011). 'An exploration of teaching strategies utilised in the facilitation of learning for first level students in general nursing science'. University of Pretoria, South Africa. http://hdl.handle.net/2263/24801. accessed on $14 / 03 / 14$ at $07: 18$ hours.

[67]. Tarrant, M. Knierim, A. Hayes and Ware, J (2006). The frequency of item writing flaws in multiple choice 


\section{Texila International Journal of Nursing \\ Volume 3, Issue 2, Dec 2017}

questions used in high stakes nursing assessments. Nurse Education Today, 26(8) $662-671$.

[68]. Tarrant, M. and Ware, J. (2008). Impact of item - writing flaws in multiple choice questions on student achievement in high - stakes nursing assessments. Journal of Medical Education, 42(2) 198 - 206. http://www.ncbi.nlm.nlh.gov/pubmed/18230093. accessed on 09/03/14 at 20:40 hours.

[69]. Titler, M. Dochterman, J. Kim, T. Kanak, M. Shever, L. Picone, D.M. Everett, L. Budreau, G. (2007). Cost of care for seniors hospitalized for hip fracture and related procedures. Nursing Outlook, 55(1), 5-14

[70]. Trochim, W. M. (2002). The Research Methods Knowledge Base, 2nd Edition. Available online at: http://trochim.human.comell.edulkb/index.htm.

[71]. Van derHorst, H. and McDonald, R. (2003). Outcome - based Education. Theory and Practice: 2nd edition. South Africa. Kagiso Publishers.

[72]. Zheng, A.Y. Lawhorn, J.K. Lumley and Freeman, S. (2008). Education forum: Application of Bloom's Taxonomy debunks the "MCAT Myth". Science, 319, 414 - 415. http://www.ncbi.nlm.nih.gov/pubmed/18218880. 